2020 is continually described as unprecedented (our world has never faced this scale of international pandemic before) and as creating a new normal (life is very quickly changing as we adapt around the world). Everything appears to be affected. This most certainly includes access to and the experience of hospitalizations and healthcare. Within newborn and infant intensive and special care nurseries, parents are being separated from their newborns and young infants because of hospital infection precautions. Healthcare professionals are tasked with providing medical care in the face of tremendous barriers, workloads and sacrifices. How do healthcare professionals, and the families they serve, understand and navigate all of this extraordinary adversity? One key to these understandings may be hearing and reflecting on the stories, the struggles and the triumphs, of everyone who is part of these systems of care. Brené Brown, PhD, LMSW, a research professor, wrote "maybe stories are just data with a soul." Families' and professionals' lived experiences, including ones of pain and suffering, may provide insight, inspiration and direction for healthcare's next steps. Much has been written on how hardship impacts individuals. For instance, Kaufman and Gregoire (2015) stated that "experiences of extreme adversity show us our own strength." (p. 146) Beyond survival, these authors optimistically described how individuals may also thrive with adversity. This capacity for resilience is a profound strength that offers stability and growth for individuals as well as for healthcare systems.

This unprecedented year is also creating challenges and a new normal for the NFI and NIDCAP efforts. NIDCAP Training
Centers and their Trainers are faced with how to educate and guide trainees and hospitals with in-person and travel restrictions. This comes at a time when individual and system-wide support is needed more than ever. How will the NFI navigate the short and long-term challenges ahead? To thrive as an organization in this rapidly changing world, the NFI must respond to the incredible realities faced by NIDCAP Trainers around the world. Examining difficulties, strengths and opportunities are crucial at this time. Drawing on the remarkable skill, passion and experience within our community, we must listen, question, discuss, reflect, learn and create with one another. Innovations for training, education and support may emerge as the NFI's members, its NIDCAP Trainers and supporters, continue to share their own experiences and perspectives with one another. Our global NFI community offers tremendous strength and wisdom to draw upon for stability and direction. Support for and from one another may lead to inspiration of creative possibilities to build future directions. The NFI, and its members, have a tremendous opportunity to rise up to meet this extremely difficult moment in time. How 2020 captures our collective hearts and imaginations and informs our next steps will ensure that the NFI and NIDCAP's capacities and reach thrive for years to come for newborns and infants and their families.

Reference:

Kaufman, S. B. \& Gregoire, C. (2015). Wired to Create: Unraveling the Mysteries of the Creative Mind. New York, NY: Perigee Books.

\title{
Greetings from the Editor
}

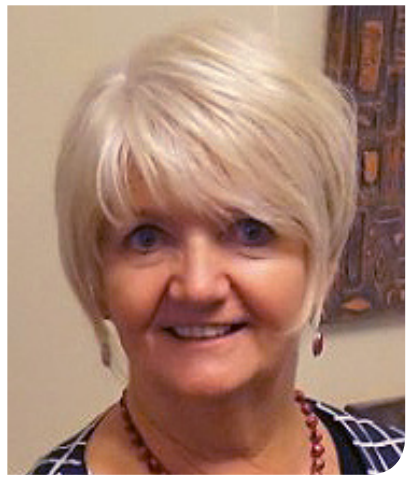

Kaye Spence, $A M$
Welcome to the second issue for 2020. What a year it has been so far. There have been many challenges for the NIDCAP community. Resilience is a prime focus at the moment.

This issue has a theme of reflection from our global community. There are a variety of interesting perspectives. Michiko Doi reflects on her journey as a NIDCAP translator in Japan, giving us a unique glimpse into her world. Bronagh McAlinden from Australia reflects on her observations of two newborn feeding episodes showing the importance of close observation. Ita Litmanovitz joins us from the Science Desk reflecting on the effects of COVID-19 through her examination of stress on the developing brain, and in our new Poet's Corner, Julia Giesen, NIDCAP Professional, reflects on her NIDCAP Training through her poetry. In our Family Voices column we hear a father's journey through the NICU with his twin daughters.
These manuscripts show the power of reflection, not only as a learning strategy but as a way of enriching the experience of the journey. We journey to Barcelona, Spain to hear about the work of the NIDCAP Training Centers and we travel to Cyprus in the Mediterranean to learn about developmental care initiatives. The Rimini team share their beautiful story of their using beauty to minimise stress in the NICU. Deborah Buehler, President of $\mathrm{NFI}$ shares her essay on what she sees as the strength of the $\mathrm{NFI}$ collective during these challenging times. The global spread of NIDCAP is evident with contributions from Japan, Australia, Canada, Israel, Italy, Spain, Cyprus and USA. We are certainly a global community.

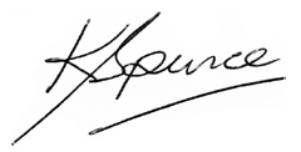

Kaye Spence AM

Senior Editor - Developmental Observer

Adjunct Associate Professor / Clinical Nurse Consultant

Australasian NIDCAP Training Centre / Sydney Children's

Hospitals Network / Western Sydney University / Australia

2 $2020 \cdot$ Developmental Observer 